\title{
POSITIVE PARENTING AS AN INTEGUMENT OF INSTINCTUAL PSYCHOSOCIAL INTERVENTION FOR SHEILDING ADOLESCENT MENTAL HEALTH-A Mixed Method Analysis
}

\author{
*Dr. P. Anitha,**Dr. V. Daisy Rani, ***Dr. B. Sathyabama \\ *Assistant Professor, Department of Social work, Holy Cross College(Autonomous), Affiliated to Bharathidasan University, \\ Trichy -2, TamilNadu , India \\ **Assistant Professor, Department of Social work, Holy Cross College(Autonomous), Affiliated to Bharathidasan University, \\ Trichy -2, TamilNadu, India \\ ***Assistant Professor, Department of Social work, Holy Cross College(Autonomous), Affiliated to Bharathidasan University, \\ Trichy -2, TamilNadu, India
}

\begin{abstract}
:
INTRODUCTION:

Community mental health covers all the beings existed in the universe. Community mental health a milestone in the field of psychiatry set up in community to promote mental health services to prevent and treat mental illnesses. The researcher adopted a sequential explanatory research design to qualitatively study the psychological and sociological perspectives of the adolescent college students hailing from both rural and urban background. The researcher conducted three focused group discussion constituting 8 members in each group and found that inadequate parenting and over controlled parenting leads them to deal with practising drugs and illegal relationship and finally lost the connection with their immediate community and social connectedness. The latest census 2011 data shows that around 41 percent of India's is below the age of 20 years. According to The Times of India, half the population is in the 20-59 age group. So focussing deinstitutionalization and treating the mental illness and preventing the same by evolving a therapeutic community can bring down the height of mental illness and prevent the upcoming worsening of mental illness among the adolescents who covers the $41 \%$ of the total population.
\end{abstract}

Keywords: adolescent, community, parenting, college students, Mental Health.

\section{INTRODUCTION:}

Adolescent is a bodily, emotional, and social changes that occur to fully occupy the attention of the adolescents. The whole concern of the adolescent in this stage is self-centred and all the worries and queries focus on 'who he is? How things moves on?' The adolescent way of thinking is rather egocentric and adolescents are quite concerned about their appearance, their impression on others, and their abilities. Also, they tend to feel to be the focus of attention of others. These intra- and interpersonal processes are placed in a multi-factorial environment where adolescents are disposed to different influences, like the influence of the family, peers, school and the media (Larson, 2002). It is up to both the environment and to the personal perception and characteristics of the individual to what extent those influences are perceived as supporting or stressful.

\subsection{REVIEW OF LITERATURE:} Mickiewicz et al., (2006) and Schofield \& Beak, (2009)postulates that, close relationships with parents can be a protective factor against poor outcomes. the protective relationship is the "secure base function" that parents continue to play in the adolescent years, particularly mothers or caregiver towards adolescent attachment have been described as, availability-helping young people to trust, sensitivity-helping young people to manage feelings and behaviors, acceptancebuilding the self-esteem of the young person; cooperation-helping young people to feel effective; and family membership-helping young people belong.

\subsection{SCOPE OF THE STUDY:}

Sharath Kumar C R,(2017) in his article acclaim that the present scenario of society is characterized as being full of anger, hatred, 
distrust, disharmony, confrontation and above all degradation of human values. At this point of time, the parents of these adolescent kids doing the graduation need to be secured and keep them intact in dealing with all the demands and challenges of the society that poses in the life of the adolescent's life. Teachers and parents have to adopt the skills of social development to make their children socially concerned and aware along with inculcating in them social behavior. There is a dire need to bring stringent changes in the community a differently therapeutic to challenge all the socially immature behavior and emotional illiteracy by introducing freedom of thought expression and autonomy in the society to be in the nest with less restriction and least disparities

\section{METHODS AND MATERIALS}

\subsection{AIM OF THE STUDY}

The Aim of the research is to study the parenting skill adopted by the adolescent college students in Trichirappalli Dt.

\subsection{OBJECTIVES}

1. To evolve the parenting style of the respondents who involved in the study

2. To find out the reason for low score through qualitative method(focus group discussion)

3. To suggest measure to imbibe positive mental health practice that carrying adolescent community

\subsection{RESEARCH METHODOLOGY:}

This chapter deals with the descriptive research strategy and outline suiting the samples and universe through which data were collected, analysed and conclusion were drawn out systematically through statistics.

\subsubsection{CONCEPTUAL FRAMEWORK:}

The study specifically manifest the parenting skill quantitatively and the low achievers are secluded for qualitative study (focus group discussion)

\subsection{Operational definition:}

\section{Parenting:}

Parenting is a family climate prevailing in the community were the individual adolescent lives with all the emotional adjustment and interpersonal adequacy influence by these parenting styles. Overall, parenting is a catalyst to buffer an individual for a matured end.

\subsection{Universe of the study}

All the 23 colleges of Aided Autonomous Arts and Science college of Tiruchirappalli city constituted the Universe. The researcher selected 3 college of Aided Autonomous Arts and Science college of Tiruchirappalli city were selected by simple Random Samplings (Lottery method)

\subsection{Sampling procedure and size}

The Researcher applied'multi Stage Random Sampling' (Bryman, A., 2004) to draw the samples for Quantitative Data from the universe. Using the inclusion criteria, all the II UG,III UG and I PG Arts and Science College of Aided Autonomous exclusive boys and girls college, and coeducation college pertaining to the Tiruchirappalli city limit were extracted . 27 respondents were selected by 'Purposive Sampling 'method that was used to collect qualitative data. A Total of 300 Samples were selected for the quantitative data. 


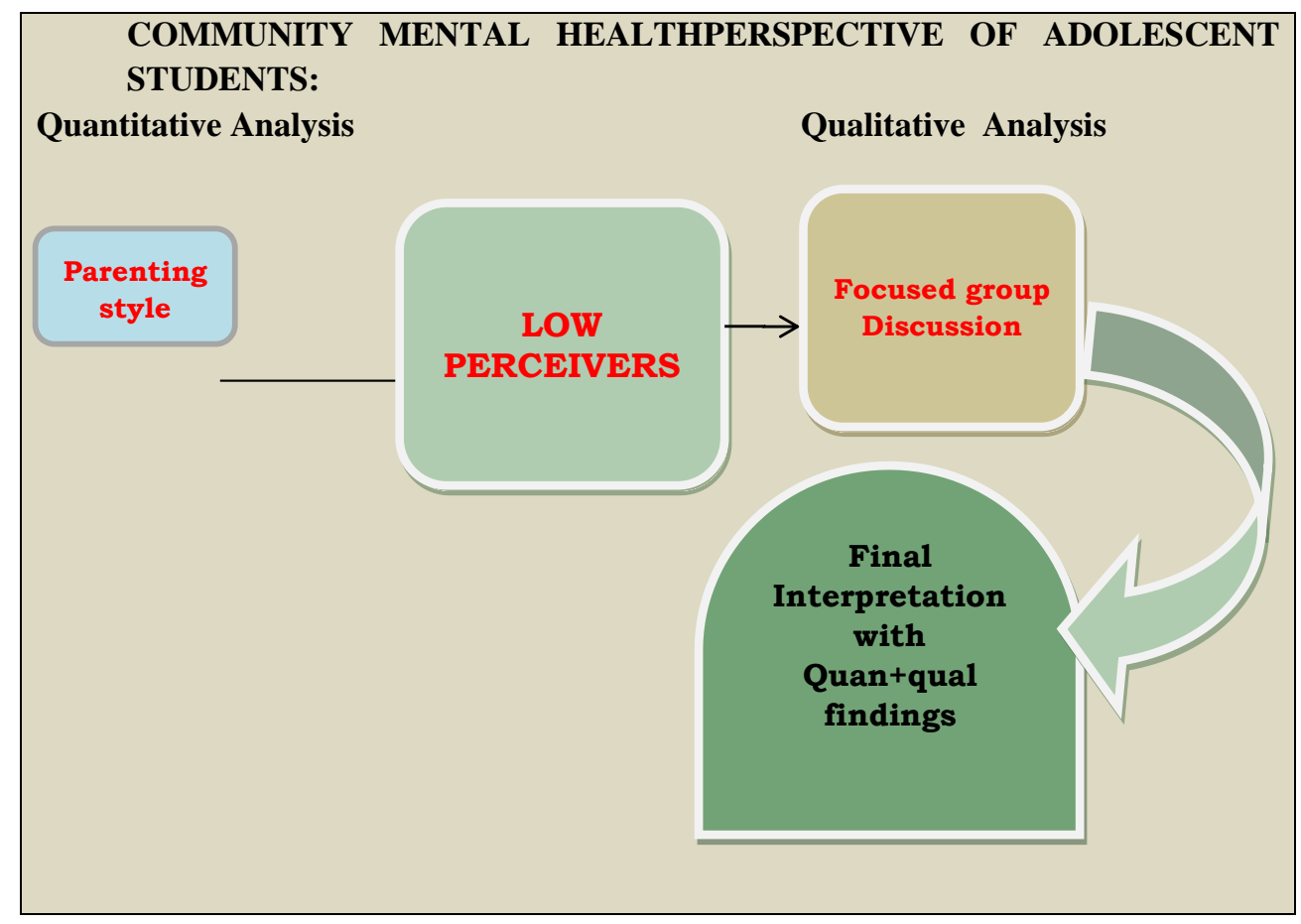

\subsection{TOOS OF DATA COLLECTION:}

R.L.Bharadwaj (1998) constructed the parenting scale. In the process of scale construction, 20 experts were asked to evaluate the different modes of parenting models by which parenting can be measured adequately. This evaluation show those eight modes of parenting emerge as most important and effective in the assessment of parent-child relationship and they are enumerated as follows:

1. Rejection Vs Acceptance,

2. Carelessness Vs Protection,

3. Neglect Vs Indulgence

4. Utopian Expectations Vs Realism.

5. Lenient Standard Vs Moralism,

6. Freedom Vs Discipline,

7. Faulty Roles Expectation Vs

Realistic Role Expectations,

8. Marital Conflict Vs Marital Adjustment.

The scales administered and the scores interpreted as three parenting styles namely parenting as whole, mothering and fathering. The coefficient of reliability for the modes of parenting is .72. The scales with lower scores: as rejection, carelessness, neglect, utopian expectation, lenient standards, freedom, faulty role expectation and marital conflict, while higher scores interpreted as: Acceptance, protection, indulgence, realism, moralism, discipline, realistic role expectation, and marital adjustment. The scores related to eight different modes of parenting and the items 36 to 40 excluded from the parenting style and interpret as the marital adjustment Vs Marital conflict

2.6.1. QUALITIATIVE METHOD:

\begin{tabular}{|l|l|l|}
\hline S.No & Methods Adopted & Data collected sources \\
\hline & Focused Group Discussion & $\begin{array}{l}\text { Focused group scripts, structured interview } \\
\text { schedule with open ended questions }\end{array}$ \\
\hline
\end{tabular}

3. RESULTS:

ANALYSIS AND INTERPRETATION:

DISTRIBUTION OF RESPONDENTS BY THEIR LEVEL OF PARENTING

\begin{tabular}{|l|c|c|c|}
\hline S.No & $\begin{array}{c}\text { Parenting styles Fathering and } \\
\text { mothering }\end{array}$ & $\begin{array}{c}\text { No of Respondents } \\
\mathrm{N}(300)\end{array}$ & $\begin{array}{c}\text { Percentage } \\
\%\end{array}$ \\
\hline
\end{tabular}




\begin{tabular}{|c|c|c|c|}
\hline S.No & $\begin{array}{c}\text { Parenting styles Fathering and } \\
\text { mothering }\end{array}$ & $\begin{array}{c}\text { No of Respondents } \\
\mathrm{N}(\mathbf{3 0 0}) \\
\end{array}$ & $\begin{array}{c}\text { Percentage } \\
\%\end{array}$ \\
\hline 1 & \multicolumn{3}{|l|}{ Rejection vs. Acceptance } \\
\hline & Low level & 168 & 56.0 \\
\hline & High level & 132 & 45.7 \\
\hline 2 & \multicolumn{3}{|l|}{ Carelessness vs. protection } \\
\hline & Low level & 138 & 56.0 \\
\hline & High level & 162 & 44.0 \\
\hline 3 & \multicolumn{3}{|l|}{ Neglect vs. Indulgence } \\
\hline & Low level & 157 & 52.3 \\
\hline & High level & 143 & 47.7 \\
\hline 4 & \multicolumn{3}{|l|}{ Utopian expectations vs. Realism } \\
\hline & Low level & 164 & 54.7 \\
\hline & High level & 136 & 45.3 \\
\hline 5 & \multicolumn{3}{|l|}{ Lenient Standard vs. Moralism } \\
\hline & Low level & 180 & 60.0 \\
\hline & High level & 120 & 40.0 \\
\hline 6 & \multicolumn{3}{|l|}{ Freedom vs. Discipline } \\
\hline & Low level & 144 & 48.0 \\
\hline & High level & 156 & 52.0 \\
\hline 7 & \multicolumn{3}{|c|}{ Faulty Role Expectations vs. Realistic Role Expectations } \\
\hline & Low level & 157 & 52.3 \\
\hline & High level & 143 & 47.7 \\
\hline 8 & \multicolumn{3}{|c|}{ Marital conflict vs. Marital adjustment } \\
\hline & Low level & 167 & 55.7 \\
\hline & High level & 133 & 44.3 \\
\hline 9 & \multicolumn{3}{|l|}{ Overall Parenting style } \\
\hline & Low level & 141 & 47.0 \\
\hline & High level & 159 & 53.0 \\
\hline
\end{tabular}

The given table explains the level of parenting style among the respondents. It clearly reveals that more than half of the respondents have high level of parental styles. But to be noted is the rest of $(47 \%)$ the half portion says to have poor fathering. Mr.J.P.Badgujar, Dr. Nisha Mundada, (2014) concluded that children with low parenting have unsatisfactory self-concept than children with high parenting style. Innovative programs on parenting methods must be planned to improve parent-child relationship during adolescence and help for better psychosocial maturity in adolescent age.

\subsection{QUALITATIVE ANALYSIS: FOCUSED GROUP DISCUSSIONS}

A focused group discussion is carefully planned discussion designed to obtain perceptions on a defined area of interest in a permissive, nonthreatening environment. Focus group discussion is one of the many tools used by researchers in the field of qualitative research. Importantly, focus groups should be developed after the rise of statistical survey methods. Focus group discussions may share the features with other qualitative approach to research. However, focus group methodology is not interchangeable with other methods and is restricted to itself in analysis. 
The convergent and the divergent findings may be applicable to other forms of research drawn based on the various groups but not

\begin{tabular}{|l|l|}
\hline \multicolumn{1}{|c|}{ Elements/ Factors } & \multicolumn{1}{c|}{ Focus group } \\
\hline Format/type & Homogenous type \\
\hline Age & 18 -21 years \\
\hline Gender & both boys and girls \\
\hline Length of each session & 40 minutes \\
\hline Number of sessions & 3 times on various dates \\
\hline Participants & $\begin{array}{l}\text { Adolescent college student doing their II UG, III UG and I PG in the } \\
\text { selected Autonomous Boys / Girls / Co-ed Colleges in Trichy district. }\end{array}$ \\
\hline Nature of Setting & Semi circle, very relaxed and facing each other for discussion purpose \\
\hline Criteria & low ratings in parenting scale \\
\hline Forms Of data & Conversation, including tone/voices and Body languages. \\
\hline Data Collection & $\begin{array}{l}5 \text { sentence completion questions given which later discussed focusing } \\
\text { the same which gives easy way to probe inside their roads }\end{array}$ \\
\hline Moderator & Flexible, focused, used, interview skills. \\
\hline Documentation Pattern & $\begin{array}{l}\text { Keen observation, verbalize recording, recording the responses of the } \\
\text { participants both verbal / non-verbal }\end{array}$ \\
\hline
\end{tabular}

In many cases, focus groups do not consist of samples of the general population, but of homogenous strata. Such composition of a group generally allows an ordinary and natural talk whereby conversation will not be impeded by huge cultural and social barriers (Krueger and Casey, 2000).

\section{Group Discussion- Outcome}

Though the respondents' hesitated to initiate the conversation after the sentence completion test; they started spontaneously volunteering in the discussion when their individual contribution was disclosed without their names.

"Society should be positive to the youngsters"

Few others expressed that society means it defines only for the upper class and the son/daughter of the highly occupied personnel.
Law, police station and educational institutions are working impartial. "Society demotivates us all"

Most of the respondents say that once their parents felt their son/daughter is grown up, total responsibilities are displaced and they totally go uncared. "My mother never cares even I come home by 3 am"," I rule and my rules only at home". Girls mutually say they get total freedom to move around, but there are times when phones are checked and bags are raided. Respondents strongly enforces that parents/teachers should not treat/guide their children by their own bitter experiences but rather they have to look upon the contextual scenarios also.

Almost all the respondents' sense that they did not achieve anything so far, for which some were able to spot out the reasons.

"My parents will never ask me where are you going? They will let me go free" 
"I am a good dancer but fear of myself itself the problem"

"No money so I am deprived of extracurricular activities"

What made them to go so uncared of self and about the future?," the immediate response is that friends and their social gang made them to do many risk taking adventurous and cinematic behaviors.

\section{Irrespective of their economic} class, all the respondents make up their appearance as an upper middle class boy or girl, for example they spend on latest out fits, trending with branded accessories, high-end mobile phones, bike, and other gadgets. Every respondent accepted that they mint excessive money from their parents more, other than fees, and spend for parties and get-togethers. While expressing their views some were regretting for their ill-mannered behavior, but some felt that there is pleasure in such activities.

Willingly knowing all the ill effects and evils, the respondents verbalize that:

"I use brown sugar and stuff"

"I drink alcohol and stay night out"

"Though not possible in my family to have a boyfriend I'm having one"

"I never tasted alcohol but now I'm an alcoholic and mentally depressed because of love failure"

\section{Closing/Summary}

The core discussion of the above FGD clearly reveals the present situation of the respondents who attended the FGD. As this group discussion focused not to teach about a guide or a manual but to learn the reason behind the low rates in quantitative analysis.Not many of the respondents were satisfied by the parenting methods they experienced. They individually grumble that either of the parents were highly vigilant while the other is totally least bothered about anything, while the male respondent say that they were given too much of freedom and trust and no monitoring. None of them were guilty for what they possess; their emotional instability and social inadequacy.

\section{Focused Group Discussion \\ Convergent findings:}

It can be inferred from the group discussion that they were in the same thought process that parents were responsible, especially their mother in some cases and father in some cases that suppressed their emotional and social maturity. All were aggressive with uncontrolled emotions in some way or the other. All the groups inevitably explained that the parenting style was not the sort they desired for.The three groups sought out the reason of bad parenting and nurturing since childhood for such immature social and emotional behavior. Lack of recognition and lack of intervention made them fall into bad company and perform many antisocial activities.

\section{Divergent findings}

When trying to arrive at a meaningful conclusion with regard to the focused discussions in relation to the individual's perspective on the style of parenting; the following are the findings that diverge and contradict the acclaims of the group discussion. Majority of the respondents from group inferred that a family handling their adolescent child brings in many success and failure stories. Parents are either not vigilant or over vigilant, which fairs poor in the development of an individual. While the other two groups surmise that controlled parenting has resulted in unpleasant childhood and it has also affected their emotional and social stability.

\section{DISCUSSIONAND CONCLUSION}

More than half of the respondents reveals higher grade in experiencing disciplined kind of mothering (52\%), and being morale (53\%), and under realism $(52 \%)$, from the perspectives of mothering. Whereas from the context of fathering, it reveals that more than half of $(52 \%)$ the respondents experiencing disciplined fathering, while concerning other type of fathering the respondents experiences lower grade of parenting from the father has been rejected, careless, neglect, in utopian expectation, lenient standards, and faulty role expectation. Inferring 
the marital adjustment between the mother and father it reveals that more than half of the $(56 \%)$ respondents' state a lower or poorer marital adjustments sensed among their parents. The qualitative analysis(focus group discussion) reveals that parental harmony will be a strength for them to face any struggles in their life. Adolescents constituting $21 \%$ of the total Indian population, there is an immediate attention alert to concentrate adolescent population, positively to ensure adequate Adolescent mental health. Most of the participants who perceived low score in the quan analysis express that they lack the trustworthiness with their parents and they are more suspicious and watch dog like to check their behaviours which intimidate them and so making them to fix with peers and distant from their parents. The natural instinctual medication for any adolescent students is their parental love and attention. Economical struggles and peer rejection can be beaten up by the matchless love their parents. If denied by the parents they in their age group forced to predate the drugs, alcohol, and various risk seeking behaviours

\section{SUGGESTION TO ENHANCE}

POSITIVE ADOLESCENT MENTAL

\section{HEALTH:}

"Parents, schools, community leaders and service providers need to listen to what young people say about what supports work for them and why, and to act on that advice by ensuring more young people are provided with the right supports sooner. With the right supports in place, a challenge in a young person's life can become an experience that builds strength and resilience."

Youth mental health needs to be a community centred:

1. School programs.

2. Peer education and support.

3. Reducing stigma.

4. Community focus.

5. Online support.

6. Culturally appropriate services. c
7. Better understanding for families, teachers and youth workers.

8. Parents has to facilitate their youth kids to be a contributing individuals

9. Assist them in identifying their passion and offer familial guidance and direct them a way with better coping skill to face the challenge.

10. Parents should give way for their growing adult children to fullu experiment their self

\section{AKNOWLEDGEMENT}

- Its a Great time ti thank my Research Adviser Dr.Umesh Samuel who stood as guide to accomplish a flawless article

- -Gratefully acknowledging the respondents' who volunteered to participate in my research and be a valuable resources

\section{REFERENCES}

[1] Creswell, J. W. (2013). Qualitative inquiry and research design: Choosing among five

[2] approaches (3rd Ed.). Thousand Oaks, CA: Sage.

[3] B.Rosy Krupa Rajitha , "Preference and Decision Making of Different Vocations During Adolescence “, International Journal of Educational Science and Research (IJESR), Vol. 7, Issue 6, pp. 6772

[4] K.Yashoda \& T.Kalyani Devi, "Influence of Home Environment and Type of School on Emotional Maturity of Adolescents “, International Journal of Environment, Ecology, Family and Urban Studies (IJEEFUS), Vol. 6, Issue 4, pp. 9-14

[5] Flammer, A. \& Alsaker, F.D. (2002). Development Psychology of Adolescence: The Resolution of Inner and External Worlds in the Age of Youth. Berne: Huber.

[6] Markiewicz, D., Lawford, H., Doyle, A., \& Haggart, N. (2006). Developmental differences in adolescents' and young adults' use of mothers, fathers, best friends and romantic partners to fulfil attachment 
needs. Journal of Youth and Adolescence, 35(1), 127-140.

[7] Richard A. Krueger \& Mary Anne Casey (2000). Focus Groups. A Practical Guide for Applied Research (3rd Edition) [10 paragraphs]. Forum Qualitative Sozialforschung / Forum: Qualitative Social Research, 3(4), Art. 28, http://nbnresolving.de/urn:nbn:de:0114-fqs0204280.

[8] Himakshi Baruah, Pragaya Dashora \& Arti Parmar , "Impact of Cyberbullying on Psychological Health of Adolescents ", International Journal of Humanities and Social Sciences (IJHSS), Vol. 6, Issue 4,pp. 137-144

[9] Manjusha Deka \& Lanu Devi , 'Understanding Adolescents' Emotionality: An Analysis of Factors Affecting Emotional Intelligence ", International Journal of Humanities and Social Sciences (IJHSS), Vol. 5, Issue 6, pp. 125-132

[10] Schofield, G., \& Beek, M. (2009). Growing up in foster care: Providing a secure base through adolescence. Child \& Family Social Work, 14, 255-266.

[11] Srinivasa Murthy, R., \& Kumar, K. (2008). Challenges of building community mental healthcare. World Psychiatry, 7(2), 101-102.

[12] Ghanshayam Thakur \& Dinesh Kumar Lahari , "A STUDY OF PSYCHOLOGICAL IMPACT ON PHYSICAL HEALTH AND FITNESS AMONG ADOLESCENTS “, BEST: International Journal of Humanities, Arts, Medicine and Sciences (BEST: IJHAMS), Vol. 4, Issue 2, pp. 117-120

[13] S.K. Srivastava \& Naveen Pant, "Social Support and Achievement Motivation among Adolescent “, BEST: International Journal of Humanities, Arts, Medicine and Sciences (BEST: IJHAMS), Vol. 3, Issue 12, pp.117-124
[14] Youth Mental Health Report Released; 20 June 2014 (C) Copyright 2014 National Mental Health Commission. 